\title{
Aspectos hematológicos de caprinos (Capra hircus) da raça Canindé criados no Rio Grande do Norte ${ }^{1}$
}

\author{
Maria G.C. Oliveira ${ }^{2 *}$, Talyta L. Nunes ${ }^{2}$, Ariana L.C. Paiva², Thayse C.G. Bezerra², \\ Naftali S. Fernandes ${ }^{2}$, André M. Vale ${ }^{2}$, Raimundo A. Barrêto Júnior ${ }^{2}$ e Valéria V. Paula ${ }^{2}$
}

\begin{abstract}
Oliveira M.G.C., Nunes T.L., Paiva A.L.C., Bezerra T.C.G., Fernandes N.S., Vale A.M., Barrêto Júnior R.A. \& Paula V.V. 2012. [Hematological aspects of Canindé goats (Capra hircus) raised in Rio Grande do Norte.] Aspectos hematológicos de caprinos (Capra hircus) da raça Canindé criados no Rio Grande do Norte. Pesquisa Veterinária Brasileira 32(Supl.1):4-8. Departamento de Ciências Animais, Universidade Federal Rural do Semi-Árido, BR110 Km 47, Cx. Postal 137, Presidente Costa e Silva, Mossoró, RN 59625900, Brazil. E-mail: glauciacarlos@hotmail.com

The objective of this paper was to study the hematological profile of Canindé breed goats (Capra hircus) raised in the state of Rio Grande do Norte, as well as the acquirement of reference values appropriate to our region. Blood samples were collected from 58 clinically healthy animals, distributed in 4 groups (males, over 5-month-old, pregnant and not pregnant females and young goats, up to 4 months of age). From a single blood sample from each animal, it was possible to perform the red blood cell (RBC) count, packed cell volume (PCV), hemoglobin, mean cell volume (MCV), mean corpuscular hemoglobin concentration (MCHC) and the white blood cell (WBC) count and differential). The obtained data was statically evaluated by the Tukey test for parametric variables and Kruskal-Wallis test followed by Dunn's test for nonparametric-level significance $(\mathrm{p}<0.05)$. The results of this study can be used as a reference for this breed of goats, making future interpretations possible from the evaluated parameters, and can support further studies in healthy or diseased animals. It shows the need for further research that demonstrates the semiarid conditions of handling and feeding, as well as assessment of variation factors on the constituents of blood taking into account sex, age and the physiological state of animals.
\end{abstract}

INDEX TERMS: Capra hircus, goats, Canindé breed, blood tests, semi-arid.

RESUMO.- Objetivou-se com este trabalho estudar o perfil hematológico de caprinos (Capra hircus) da raça Canindé, criados no Estado do Rio Grande do Norte, como também a busca de valores de referência que se adequem à nossa região. Foram coletadas amostras sanguíneas de 58 animais clinicamente sadios, distribuídos em 4 grupos (machos acima de 5 meses, fêmeas gestantes, fêmeas não gestantes e filhotes até 4 meses de idade). A partir de única amostra de sangue de cada animal foram realizados o eritrograma (contagem de hemácias, hematócrito, hemoglobina, volume corpuscular médio e concentração de hemoglobina corpuscular média) e o leucograma (contagem total e di-

\footnotetext{
${ }^{1}$ Recebido em 8 de fevereiro de 2012.

Aceito para publicação em 17 de setembro de 2012.

2 Departamento de Ciências Animais, Universidade Federal Rural do Semi-Árido (UFERSA), BR110 Km 47, Cx. Postal 137, Presidente Costa e Silva, Mossoró, RN 59625-900, Brasil. *Autor para correspondência: glauciacarlos@hotmail.com
}

ferencial de leucócitos). Os dados obtidos foram avaliados por meio do teste de Tukey para variáveis paramétricas e Kruskal-Wallis seguido pelo teste de Dunn para não paramétricos em nível de significância de $(\mathrm{p}<0.05)$. Os resultados apontam para existência de maiores quantidades de He nos machos adultos e fêmeas não gestantes, diferente do que ocorre com o VCM; já com relação ao leucograma temos que os eosinófilos mostram-se mais elevados nas fêmeas adultas e os monócitos se elevam quando na presença da gestação. Os valores deste trabalho podem servir de referência para raça Canindé, tornando possível futuras interpretações para os parâmetros verificados, além de subsidiar novos estudos em animais hígidos ou doentes. Mostra a necessidade de pesquisas que evidenciem as condições semiáridas de manejo e alimentação, bem como a avaliação dos fatores de variação, sobre constituintes do sangue, que levem em conta o sexo, a idade e estado fisiológico dos animais. 
TERMOS DE INDEXAÇÃO: Capra hircus, caprinos, Canindé, hemograma, semiárido.

\section{INTRODUÇÃO}

As raças nativas de caprinos possuem interessante material genético para condições do semiárido, se destacando entre elas a raça Canindé. Acredita-se que esta raça tenha se originado no vale do Canindé, no Estado do Piauí no Nordeste do Brasil e que em sua formação tenha participação da raça Grisone Negra da Suíça. A adaptabilidade destes animais às condições de semiárido, os tornam um recurso genético importante, visando o processo de cruzamento com raças exóticas e melhoria da capacidade adaptativa destas raças a serem introduzidas. Porém, nos últimos anos, tem sido observado redução do número desses animais devido ao cruzamento com raças exóticas, visando à obtenção de indivíduos com maior potencial leiteiro, resultando em imponente risco de extinção dessa raça (Mariante 1993, Sousa 2010).

Ações que objetivem a preservação dos mesmos são imprescindíveis, já que as pesquisas são escassas, sobretudo no tocante ao conhecimento do perfil hematológico da espécie, observando-se, na verdade, que a maioria dos trabalhos sobre hematologia baseiam-se em valores procedentes de outras regiões com condições diferentes (Bezerra et al. 2008).

Segundo Ndoutamia \& Ganda (2005) a hematologia clínica constitui-se em importante área de estudo sobre o estado de saúde dos animais. Entretanto, para adequada interpretação do hemograma é necessário considerar a influência dos fatores de variabilidade, como: condições climáticas e ambientais, estado nutricional, gestação, lactação, manejo, raça, sexo e idade.

Nesse contexto, essa pesquisa objetivou mostrar o aspecto hematológico de caprinos da raça Canindé criados na região semiárida do nordeste brasileiro, uma vez que os valores referência utilizados são oriundos de pesquisas de outras regiões com clima, pastagens, sistema de criação e animais de linhagem genética diferentes.

\section{MATERIAL E MÉTODOS}

O estudo foi aprovado pela Comissão de Ética no Uso de Animais da UFERSA. Sendo o protocolo de aprovação CEUA/UFERSA 23091.002676/10-99.

Foram utilizados 58 caprinos (Capra hircus) clinicamente hígidos, de faixa etária variada, machos e fêmeas da raça Canindé, oriundos de propriedades rurais do estado do Rio Grande do Norte. Os animais foram distribuídos em 4 grupos experimentais. 0 grupo I foi formado por 20 fêmeas não gestantes; grupo II composto por 11 cabritos (machos e fêmeas) até 4 meses de idade; grupo III contendo 20 fêmeas em diferentes estágios de gestação e o grupo IV formado por 7 machos acima de 5 meses de idade.

Antes da coleta de sangue os animais passaram por exame físico geral que consistiu na aferição das frequências cardíaca e respiratória, pressão arterial sistólica, diastólica e média, temperatura retal, coloração das mucosas e tempo de preenchimento capilar.

Foi colhido $5 \mathrm{~mL}$ de sangue, por punção da veia jugular, com seringa e agulha descartáveis, que foram acondicionados em tubos contendo uma gota do ácido etileno-diamino-tetracético (EDTA).
Para determinação do hematócrito (Ht - \%) foi utilizada a técnica do microhematócrito por 10 minutos, utilizando microcapilares homogêneos de 75 milímetros de comprimento por um milímetro de diâmetro, e microcentrífuga (Sigma $1-15^{\circledR}$ ) para Ht. A hemoglobina ( $\mathrm{Hb}-\mathrm{g} / \mathrm{dL})$ foi dosada através de espectofotometria semi-automática em aparelho Bioplus Bio $2000^{\circledR}$. A contagem total de hemácias $\left(\mathrm{He}-\mathrm{x} 10^{6} / \mu \mathrm{L}\right)$ foi feita em câmara do tipo Neubauer modificada, sendo para tanto, a diluição das células realizada mediante uso de pipetadores semiautomáticos onde aspiravam-se $5 \mu \mathrm{L}$ de sangue juntamente com $2 \mathrm{~mL}$ de solução fisiológica, este conteúdo era então homogeneizado lentamente, colocado na câmara Neubauer e feita a contagem total de eritrócitos nos campos adequados, usando para tal microscópio Olympus $\mathrm{CX} 41^{\circledR}$. Os índices hematimétricos absolutos: volume corpuscular médio (VCM - fL) e concentração de hemoglobina corpuscular média (CHCM - \%) foram obtidos a partir da contagem do número de $\mathrm{He}$, do $\mathrm{Ht}$ e do teor de $\mathrm{Hb}$, por meio de fórmulas convencionais.

A contagem global de leucócitos (Le - cél $/ \mathrm{mm}^{3}$ ) foi realizada em câmara do tipo Neubauer através de pipetadores semi-automáticos, onde aspiravam-se $10 \mu \mathrm{L}$ de sangue juntamente a $200 \mu \mathrm{L}$ o diluidor de leucócitos. Este conteúdo era homogeneizado lentamente, colocado na câmara Neubauer e feita contagem total de leucócitos nos campos adequados. A leitura foi feita no microscópio Olympus $\mathrm{CX} 41^{\circledR}$. A contagem diferencial de Le foi feita utilizando sangue in natura através da confecção de esfregaços sanguíneos, corados com coloração panótica rápida Instant- Prov $\left(\right.$ New Prov $^{\circledR}$ ) e examinados ao microscópio Olympus CX41 ${ }^{\circledR}$, com objetiva de imersão a óleo (100x), segundo técnica padronizada por Birgel Júnior (2001). Em cada esfregaço sanguíneo foram diferenciados 100 leucócitos, classificados de acordo com suas características morfológicas e tintoriais em neutrófilos com núcleo segmentado, eosinófilos, linfócitos e monócitos. E por fim, foram calculados os valores absolutos de cada tipo de Le a partir de prévia contagem relativa.

Os resultados foram avaliados pelo teste de Kolmogorov-Smirnov. Após verificação da normalidade dos dados, a análise estatística foi conduzida utilizado o teste de ANOVA, seguido pelo teste de Tukey para variáveis paramétricas e Kruskal-Wallis seguido pelo teste de Dunn para não paramétricos. Os dados foram expressos em média e desvio padrão, avaliados pelo programa estatístico BioEstat versão 5.0. Valores de $\mathrm{p}<0,05$ foram considerados significativos.

\section{RESULTADOS}

Os resultados mostraram que não existiu diferença estatística significativa $(\mathrm{p}<0.05)$ entre grupos estudados sobre os valores de Ht. As fêmeas não gestantes apresentaram maiores quantidades de He em relação ao grupo dos cabritos e ao grupo das fêmeas gestantes $(\mathrm{p}<0,05)$, porém manteve quantidade de He igual ao do grupo dos machos. A Hb foi outro valor que não variou entre os grupos estudados, assim como a CHCM. O VCM foi maior no grupo de fêmeas gestantes que não gestantes $(\mathrm{p}<0.05)$, não sendo observada diferença entre outros grupos (Quadro 01).

Os resultados revelaram que não existiu diferença $(p<0.05)$ entre os grupos estudados sobre os valores totais de Le. Quanto ao diferencial dos tipos de Le, no parâmetro de eosinófilos, as fêmeas gestantes apresentaram maiores valores que os machos e filhotes $(\mathrm{p}<0.05)$, não diferindo das fêmeas não gestantes. Este mesmo grupo Mostrou maiores quantidades de monócitos em relação ao grupo 
Quadro 1. Valores de média e desvio padrão do eritrograma para machos, gestantes, filhotes e fêmeas não gestantes de caprinos Canindé criados no Rio Grande do Norte. Mossoró, 2011

\begin{tabular}{lcccc}
\hline Variáveis & Machos & Gestantes & Filhotes & Não Gestantes \\
\cline { 2 - 5 } & Média $\pm \mathrm{DP}$ & Média $\pm \mathrm{DP}$ & Média $\pm \mathrm{DP}$ & Média \pm DP \\
\hline $\mathrm{Ht}(\%)$ & $34.28 \pm 8.82^{\mathrm{a}}$ & $33.95 \pm 5.93^{\mathrm{a}}$ & $30.63 \pm 6.93^{\mathrm{a}}$ & $32.15 \pm 5.16^{\mathrm{a}}$ \\
$\mathrm{He}\left(\mathrm{x} 10^{6} / \mu \mathrm{L}\right)$ & $16.84 \pm 5.61^{\mathrm{ab}}$ & $14.61 \pm 7.45^{\mathrm{a}}$ & $12.63 \pm 2.47^{\mathrm{a}}$ & $16.57 \pm 3.24^{\mathrm{b}}$ \\
$\mathrm{Hb}(\mathrm{g} / \mathrm{dL})$ & $11.05 \pm 2.84^{\mathrm{a}}$ & $10.94 \pm 1.91^{\mathrm{a}}$ & $9.87 \pm 2.23^{\mathrm{a}}$ & $10.36 \pm 1.65^{\mathrm{a}}$ \\
$\mathrm{CHCM} \mathrm{( \% )}$ & $32.25 \pm 0.006^{\mathrm{a}}$ & $32.24 \pm 0.03^{\mathrm{a}}$ & $32.32 \pm 0.32^{\mathrm{a}}$ & $32.23 \pm 0.05^{\mathrm{a}}$ \\
$\mathrm{VCM}(\mathrm{fL})$ & $20.85 \pm 3.23^{\mathrm{ab}}$ & $26.95 \pm 8.78^{\mathrm{a}}$ & $24.45 \pm 6.03^{\mathrm{ab}}$ & $20.35 \pm 4.01^{\mathrm{b}}$
\end{tabular}

$\mathrm{Ht}=$ Hematócrito, $\mathrm{He}=$ hemáceas, $\mathrm{Hb}=$ hemoglobina, $\mathrm{CHCM}=$ concentração de hemoglobina globular média, VCM = volume globular médio, DP = Desvio padrão. a,b Letras diferentes significam diferença estatística entre os grupos $(\mathrm{p}<0.05)$.

Quadro 2. Valores de média e desvio padrão do leucograma para machos, fêmeas gestantes, filhotes e fêmeas não gestantes de caprinos Canindé criados no Rio Grande do Norte

\begin{tabular}{lcccc}
\hline \multirow{2}{*}{$\begin{array}{c}\text { Variáveis } \\
\left.\text { (células } / \mathrm{mm}^{3}\right)\end{array}$} & Machos & Gestantes & Filhotes & Não Gestantes \\
\cline { 2 - 5 } \multicolumn{1}{c}{ Leucócitos totais } & $10857.14 \pm 1258.44^{\mathrm{a}}$ & $12685 \pm 4097.91^{\mathrm{a}}$ & $12090.90 \pm 4388.32^{\mathrm{a}}$ & $12627.5 \pm 3418.31^{\mathrm{a}}$ \\
Neutrófilos Segmentados & $5606.14 \pm 1381.99^{\mathrm{a}}$ & $7452.2 \pm 2994.83^{\mathrm{a}}$ & $5171.72 \pm 2704.67^{\mathrm{a}}$ & $6334.9 \pm 2051.25^{\mathrm{a}}$ \\
Eosinófilos & $295.28 \pm 209.41^{\mathrm{ab}}$ & $995 \pm 1005.89^{\mathrm{c}}$ & $201.81 \pm 221.87^{\mathrm{b}}$ & $908.9 \pm 975.78^{\mathrm{ac}}$ \\
Linfócitos & $4797.71 \pm 1336.78^{\mathrm{a}}$ & $3829.8 \pm 1735.97^{\mathrm{a}}$ & $6565.90 \pm 3353.77^{\mathrm{a}}$ & $4712.9 \pm 1819.42^{\mathrm{a}}$ \\
Monócitos & $315.28 \pm 165.52^{\mathrm{ab}}$ & $507.2 \pm 320.15^{\mathrm{a}}$ & $317.27 \pm 248.13^{\mathrm{ab}}$ & $305 \pm 240.15^{\mathrm{b}}$
\end{tabular}

$\overline{\mathrm{DP}}=$ desvio padrão. a,b, c Letras diferentes significam diferença estatística entre os grupos $(\mathrm{p}<0.05)$.

das fêmeas não gestantes. Os demais tipos celulares, neutrófilos segmentados e linfócitos, não mostraram diferença $(\mathrm{p}<0.05)$ em nenhum dos grupos estudados. Em todas as contagens diferenciais de leucócitos não se observou à presença de basófilos. (Quadro 02).

\section{DISCUSSÃO}

Os machos adultos apresentaram Ht divergentes dos observados por Egbe-Nwiyi, Nwaosu \& Salami (2000) ao estudarem hematologia de caprinos na Nigéria, no qual encontraram Ht de $44.1 \pm 0.69 \%$ mostrando a diferença do clima e raça sobre este parâmetro, visto que na Nigéria a temperatura máxima é de $32^{\circ} \mathrm{C}$, composta por alta umidade relativa do ar e índices pluviométricos relativamente elevados e bem distribuídos durante todo o ano. Contudo, no semiárido potiguar, as chuvas são escassas e mal distribuídas e os animais estudados chegavam a atingir temperatura retal de até $40,8^{\circ} \mathrm{C}$.

$\mathrm{O}$ valor de $\mathrm{He}$ encontrou-se de acordo com os apresentados por Hawkey et al. (1984), que se elevou com o desenvolvimento etário, justificando-se que o aumento de He coincidiu com o período em que os animais foram desmamados e passaram, portanto, a ingerir efetivamente alimentos sólidos, o que poderia refletir a falta de ferro na dieta do lactante. Fatos semelhantes também foram relatados por outros autores, que estudaram anemia em cordeiros associada à deficiência de ferro (Green et al. 1997, Vatn \& Framstad 2000). A diferença verificada entre o grupo das gestantes quando comparado ao das fêmeas não gestantes (Quadro 1) foi semelhante à apresentada por diversos autores Azab \& Abdel-Maksoud (1999), Mbassa \& Poulsen (1991). Discordou-se, entretanto, de Nfi (1991) que relatou a inexistência de alterações no número de He de cabras gestantes, e também de estudos com ovelhas gestantes e vazias desenvolvidos por Brito et al. (2006).
Valores de $\mathrm{Hb}$ foram semelhantes aos obtidos por Luz et al. (2010) ao estudarem caprinos Canindé no Rio Grande do Norte. Também ocorreu similaridade com os resultados de Bezerra et al. (2008), Duarte et al. (2009) e Silva et al. (2008) ao estudarem caprinos Moxotó do Nordeste brasileiro. Os resultados do presente estudo foram inferiores aos relatados por Paes, Baironi \& Fonteque (2000) que realizaram trabalho com raça Parda Alpina.

Os resultados encontrados para CHCM discordaram de Paes, Baironi \& Fonteque (2000) ao obterem média de $39,63 \%$ para caprinos da raça Pardo Alpina. E também ocorreu divergência da pesquisa de Bezerra et al. (2008) com caprinos no semiárido paraibano e ainda de estudo com cabras Saanen (Viana et al. 2002). No entanto, a média dessa variável se apresentou dentro da normalidade para a espécie, oscilando de 30 a 36 (Kramer 2006, Luz et al. 2010).

Todos os valores de VCM achados na pesquisa estavam dentro da média para a espécie, conforme Kramer (2006). Os dados para fêmeas gestantes foram divergentes dos encontrados por Fonteque et al. (2010) que observaram a $\mathrm{Hb}$ de cabras Saanen gestantes com valor de 18,35 $\pm 1,93$, e em cabras não gestantes, com resultado de 18,54 $\pm 1,04$, não mostrando, portanto, influência da gestação sobre este parâmetro. 0 aumento significativo $(\mathrm{p}<0,05)$ no valor de VCM visto no grupo das gestantes quando comparado ao grupo das não gestantes pode ser explicado pelo fato de que na gestação, o VCM aumenta, podendo mascarar uma deficiência de ferro, e, portanto, não sendo fidedigno para classificação de possível anemia (Moura \& Pedroso 2003, Rodrigues \& Jorge 2010).

Com relação ao leucograma, os resultados corroboraram com Bezerra et al. (2008) e Souza et al. (2006), que não observaram diferença significativa $(\mathrm{p}<0,05)$ para Le, ao avaliar o leucograma de caprinos mestiços dos mesmos 
grupos raciais. No entanto, discordaram da dinâmica em relação à idade encontrada por Birgel Júnior et al. (2001) ao estudarem bovinos da raça Jersey.

Os valores de neutrófilos segmentados e linfócitos observados estão de acordo com Bezerra et al. (2008) e Duarte et al. (2009). Os cabritos demonstraram maior quantidade de linfócitos, fato esse que está em concordância com aqueles referidos na literatura brasileira (Ferreira Neto et al. 1982, Birgel 1969). Os resultados ainda equiparam-se aos de Souza et al. (2006) que demonstraram média linfocitária de $5780 \pm 1600$ (cél. $/ \mathrm{mm}^{3}$ ) para cabras Saanen adultas.

Existiu uma disparidade entre valores de eosinófilos para os diferentes grupos, mas todos encontraram-se dentro da média, concordando com Bezerra et al. (2008), Silva (2008). No entanto, discordaram dos valores expostos por Ayres et al. (2009) ao apresentarem dados médios de eosinófilos para caprinos da raça Anglo-nubiana de 1540 \pm 1780 (cél. $/ \mathrm{mm}^{3}$ ) e para raça Saanen de $2016 \pm 2240$ (cél. $/ \mathrm{mm}^{3}$ ). O número absoluto de eosinófilos de caprinos Canindé não sofreu influência da gestação, estando essas observações em concordância com as relatadas na literatura por Mbassa \& Poulsen (1991) e Azab \& Abdel-Maksoud (1999). Assim como na pesquisa de Birgel Júnior et al. (2001), os animais jovens tiveram número de eosinófilos abaixo da média dos adultos. A não diferença apresentada quando o valor de eosinófilos dos filhotes foi comparada ao dos machos pode ser explicada pelo fato de que grande parte dos machos que participaram do estudo tinham idade abaixo dos 12 meses. Os machos não foram classificados como cabritos, porque nesta espécie a capacidade de fecundação ocorre por volta dos 140-150 dias. Diferentemente do que acontece com as fêmeas, onde em raças caprinas locais do nordeste do Brasil (Canindé, Marota, Moxotó e Repartida), a puberdade pode ocorrer por volta dos 360 dias de idade (Simplício et al. 1990).

Os dados de monócitos do grupo dos cabritos assemelharam-se aos encontrados em estudo com cabras sem padrão racial definido de até 12 meses de idade (Bezerra et al. 2008). Outro dado também determinado por estes autores se assemelharam ao encontrado na presente pesquisa, que correspondeu ao valor médio de $147 \pm 705$ para animais adultos. 0 fato das fêmeas gestantes terem apresentado valor diferente $(\mathrm{p}<0.05)$ do visto nas fêmeas não gestantes também foi observado por Viana et al. (2002) ao estudarem cabras Saanen. Entretanto, na literatura consultada nenhum autor fez referência à possível influência da gestação sobre o número de monócitos (Mbassa \& Poulsen 1991, Azab \& Abdel-Maksoud 1999).

\section{CONCLUSÕES}

Observamos a existência de maiores quantidades de $\mathrm{He}$ nos machos adultos e fêmeas não gestantes, diferente do que ocorre com o VCM, que se eleva significativamente com a gestação nessa raça.

Com relação à série branca, vimos que os eosinófilos mostram-se mais elevados nas fêmeas adultas e os monócitos se elevam quando da presença da gestação.

Os dados obtidos podem servir de referência para a raça de caprinos Canindé, além de subsidiarem novos estudos e futuras interpretações laboratoriais em animais hígidos ou doentes. Tornam-se necessárias pesquisas que evidenciem as condições semiáridas de manejo e alimentação, bem como a avaliação dos fatores de variação sobre os constituintes do sangue que levem em consideração o sexo, a idade e estado fisiológico dos animais.

Agradecimentos.- Ao CNPq (562975/2010-1) pelo apoio financeiro e aos criadores de caprinos Canindé do Rio Grande do Norte e UFERSA.

\section{REFERÊNCIAS}

Ayres M.C.C., Dorea R.D., Birgel Junior E.H., Viana R.B., Lara M.C.C.S.H., Bittencourt T.C.B.S.C. \& Birgel E.H. 2009. Dinâmica do leucograma de caprinos jovens, do nascimento até seis meses de idade: influência do fator racial. Ciênc. Anim. Bras. 10(Supl.1):261-265.

Azab E.M. \& Abdel-Maksoud H.A. 1999. Changes in some hematological and biochemical parameters during prepartum and postpartum periods in female Baladi goats. Small Rumin. Res. 34(1):77-85.

Bezerra L.R., Ferreira A.F., Camboim E.K.A., Justiniano S.V., Machado P.C.R. \& Gomes B.B. 2008. Perfil hematológico de cabras clinicamente sadias criadas no cariri paraibano. Ciênc. Agrotec. 32(3):955-960.

Birgel E.H. 1969. Estudo do quadro leucocitário de caprinos (Capra hircus, L.) normais, criados no Estado de São Paulo. Influência dos fatores raciais, sexuais, etários e alimentares. Tese de Doutorado, Faculdade de Medicina Veterinária e Zootecnia, Universidade de São Paulo, São Paulo.

Birgel Júnior E.H., D’angelino J.L., Benesi F.J. \& Birgel E.H. 2001. Valores de referência do leucograma de bovinos da raça Jersey criados no Estado de São Paulo. Braz. J. Vet. Res. Anim. Sci. 38(3):136-141.

Brito M.A., González D.F., Ribeiro L.A., Campos R., Barbosa L.L.P.R. \& Bergmann G. 2006. Composição do sangue e do leite em ovinos leiteiros do sul do Brasil: variações na gestação e na lactação. Ciência Rural 36(3):942-948.

Duarte A.L.L., Cattelan J.W., Araújo M.G., Cattelan R.J.G. \& Vicente W.R.R. 2009. Hemograma e bioquímica sanguínea de caprinos submetidos à biópsia hepática com agulha tru-cut guiada por videolaparoscopia. Ars Vet. 25(2):47-53.

Egbe-Nwiyi T.N., Nwaosu S.C. \& Salami H.A. 2000. Haematological values of appararently healthy sheep and goats as influenced by age and sex in arid zone of Nigeria. Afr. J. Biomed. Res. 3(2):109-115.

Ferreira Neto J.M., Marques Júnior A.P., Carvalho M.M. \& Ferreira P.M. 1986. Hemograma de caprinos do nascimento até um ano de idade. Arq. Bras. Med. Vet. Zootec. 38(5):645-656.

Fonteque J.H., Takahira R.K., Saito M.E., Valente A.C.S., Barion G. \& Kohayagawa A. 2010. Eritrograma e metabolismo do ferro e concentração sérica de eritropoetina em fêmeas caprinas da raça saanen nos períodos de gestação, parto e pós-parto. Pesq. Vet. Bras. 30(11):991-995.

Green L.E., Graham M. \& Morgan K.L. 1997. Preliminary study of effect of iron dextran on a non-regenerative anaemia of housed lambs. Vet. Rec. 140(9):219-222.

Hawkey C.M., Hart M.G. \& Fitzgerald A.K. 1984. Haematological values in mouflon (Ovis musimon): influence of age, sex, season and vitamin E status. Res. Vet. Sci. 36(1):37-42.

Kramer J.W. 2006. Normal hematology of cattle, sheep and goats, p.10751084. In: Feldman B.F., Zinkl J.G. \& Jain N.C. (Eds), Schalm's Veterinary Hematology. $5^{\text {th }}$ ed. Williams and Wilkins, Philadelphia.

Luz D.O., Lacerda R.M., Barrêto Júnior R.A. \& Soto-Blanco B. 2010. Eritrograma e variantes de hemoglobina em caprinos da raça Canindé. Arq. Bras. Med. Vet. Zootec. 62(1):208-210.

Mariante A.S. 1993. Conservação de recursos genéticos animais: uma questão de bom senso. Anais 30ª Reunião Anual da Sociedade Brasileira de Zootecnia, Rio de Janeiro, RJ, p.175-182. (Resumo)

Mbassa G.K. \& Poulsen J.S.D. 1991. Influence of pregnancy, lactation and environment on haematology profiles in Danish Landrace dairy goats (Capra hircus) of different parity. Comp. Biochem. Physiol. B 100(2):403-412. 
Moura L.C. \& Pedroso M.A. 2003. Anemia ferropriva na gestação. Revta Enferm. UNISA 4:70-75.

Ndoutamia G. \& Ganda K. 2005. Determination des paramétres hematologiques et biochemiques des petits ruminants du Tchad. Revta Med. Vet. 156(4):202-206.

Nfi A.N. 1991. Haematological reference values and other blood characteristics of small ruminants at Mankon-Cameroon. 1. Haematological values. Bull. Anim. Health. Prod. Afr. 39(2):243-245.

Paes P.R., Baironi G. \& Fonteque J.R. 2000. Comparação dos valores hematológicos entre caprinos fêmeas da raça Parda Alpina de diferentes faixas etárias. Vet. Not. 6(1):43-49.

Rodrigues L.P. \& Jorge S.R.P.F. 2010. Deficiência de ferro na gestação, parto e puerpério. Revta Bras. Hematol. Hemoter. 32(2):53-56.

Silva E.M.N., Souza B.B., Silva G.A., Cézar M.F., Freitas M.M.S. \& Benício T.M.A. 2008. Avaliação hematológica de caprinos exóticos e nativos no semi-árido paraibano. Ciênc. Agrotec. 32(2):561-566.
Simplício A.A., Pereira de Figueiredo E.A., Riera G.S. \& Foote W.C. 1990. Puberty in four genotypes of female goats in Northeast Brazil. Pesq. Agropec. Bras. 25(3):455-459.

Sousa, F.C. 2010. Desenvolvimento folicular em resposta a diferentes tratamentos de estimulação ovariana em cabras Canindé avaliadas por ultrassonografia. Dissertação de Mestrado, Faculdade de Veterinária, Universidade Estadual do Ceará, Fortaleza.

Souza C., Lopes S.T.A., Batina P.N., Cecim M., Cunha C.M., Conrado A.C. \& Beck A. 2006. Estresse parasitário em cabras Saanen: avaliação hematológica e da atividade oxidativa dos neutrófilos. Vet. Notícias 12(2):17-23.

Vatn S. \& Framstad T. 2000. Anaemia in housed lambs: effects of oral iron on clinical pathology and performance. Acta Vet. Scand. 41(3):273-281.

Viana R.B., Birgel Júnior E.H., Ayres M.C.C., Benesi F.J., Mirandola R.M.S. \& Birgel E.H. 2003. Influência da gestação e do puerpério sobre o eritrograma de caprinos (Capra hircus) da raça Saanen, criados no estado de São Paulo. Braz. J. Vet. Res. Anim. Sci. 40(3):196-201. 